\title{
Micelle Directed Synthesis of Polyoxometalate Nanoparticles and Their Improved Catalytic Activity for the Aerobic Oxidation of Sulfides \\ Galia Maayan, ${ }^{\mathrm{a}}$ Ronit Popovitz-Biro and Ronny Neumann ${ }^{\mathrm{a} *}$ \\ (a) Department of Organic Chemistry and (b) Department of Materials and Interfaces, Weizmann Institute of Science, Rehovot, Israel, 76100
}

\section{Detailed Experimental Section}

Materials. Hydrophilic silica $380 \mathrm{~m}^{2} / \mathrm{g}$ AEROSIL 380, supplied by Degussa; Hydrophobic silica $100 \mathrm{~m}^{2} / \mathrm{g}$ AEROSIL R202, supplied by Degussa; Silica gel granulated 3-6 mm, supplied by Fluka; $\alpha$-alumina $99.5+\%$, supplied by Strem Chemicals; $\gamma$-alumina $97.7 \%$, supplied by Strem Chemicals. $\mathrm{H}_{3} \mathrm{PMo}_{12} \mathrm{O}_{40}$ was purchased from Aldrich $\mathrm{H}_{5} \mathrm{PV}_{2} \mathrm{Mo}_{10} \mathrm{O}_{40}$ was prepared according to a literature method (Tsigdinos, G. A.; Hallada, C. J. Inorg. Chem. 1968, 7. 437-441).

\section{Instrumentation.}

Cryo-TEM. FEI (Philips) Tecnai F20 (200kV, FEG). Schottky field emission source, TWIN objective lens, CompuStage, Rotation-free magnification; Specimen tilt: $\pm 70^{\circ}$. Holders: Single tilt, Gatan cryo holder, Fischione rotation holder 2020; Accessories: low dose unit, Tietz 4k x 4k single-port slow scan CCD camera; Point resolution $0.27 \mathrm{~nm}$.

HRTEM. FEI (Philips) Tecnai F30 U-Twin (300kV, FEG). Specimen tilt: $\pm 30^{\circ}$; Holders: double tilt; Accessories: GIF (Gatan imaging filter for elemental mapping and EELS analysis); Point resolution: $1.7 \AA$.

Preparation of cesium dodecylsulfate $(C D S)$. A saturated water solution of sodium dodecylsulfate $(1 \mathrm{~g}, 3.5$ mmole) was treated with $5 \% \mathrm{HCl}$ (a few drops) to get $\mathrm{pH} \sim 0$. This mixture was treated with a saturated water solution of cesium carbonate $(0.75 \mathrm{~g}, 5 \mathrm{mmole})$ and white waxy solid (CDS) was precipitated upon stirring. The product was collected by vacuum filtration and dried $(0.96 \mathrm{~g}, 2.5 \mathrm{mmole}, 72 \%$ yield $)$.

Preparation of $\mathrm{H}_{3} \underline{\mathrm{PMo}_{12}} \mathrm{O}_{40}$ polyoxometalate nanoparticles. A mixture of $200 \mu \mathrm{L}$ of a $0.01 \mathrm{M}$ $\mathrm{H}_{3} \mathrm{PMo}_{12} \mathrm{O}_{40}$ water solution and $800 \mu \mathrm{L}$ of a $0.1 \mathrm{M}$ water solution of polyvinylpyrrolidone (PVP) was added to $500 \mu \mathrm{L} 0.01 \mathrm{M}$ water solution of CDS, in a sonicator bath for 5 minutes. After the formation of the nanoparticles was completed, PVP was extracted from the water solution with chloroform ( $2 \mathrm{ml} \mathrm{x} 3)$.

Preparation of $H_{5} \underline{P} V_{2} \underline{M o_{10}} \underline{O}_{40}$ polyoxometalate nanoparticles. A mixture of $200 \mu \mathrm{L}$ of a $0.01 \mathrm{M}$ $\mathrm{H}_{5} \mathrm{PV}_{2} \mathrm{Mo}_{10} \mathrm{O}_{40}$ water solution and $800 \mu \mathrm{L}$ of a $0.1 \mathrm{M}$ water solution of polypropylene glycol (PPG, Mw $=750$ ) was added to $500 \mu \mathrm{L}$ of a $0.01 \mathrm{M}$ water solution of CDS, in a sonicator bath for 5 minutes. After the formation of the nanoparticles was completed, they were supported on hydrophilic silica $(4.8 \mathrm{mg}, 10 \% \mathrm{w} / \mathrm{w})$ by stirring under heating until the water evaporated and the supported catalyst remained dry (10.6 mg is equivalent to $2 \mu \mathrm{mol}_{5} \mathrm{PV}_{2} \mathrm{Mo}_{10} \mathrm{O}_{40}$ ).

Characterization of $\mathrm{H}_{3} \mathrm{PMo}_{12} \mathrm{O}_{40}$ nanoparticles by Cryo-TEM. A sample of the $\mathrm{H}_{3} \mathrm{PMo}_{12} \mathrm{O}_{40}$ nanoparticle solution $(4 \mu \mathrm{L})$ was deposited on a quantifoil multi A grid blotted with filter paper and plunged with liquid ethane using a costumer freeze plunger. The sample was transferred to a 
FEI F-20 TEM using a Gatan cryo holder and observed under low dose conditions at an acceleration voltage of $200 \mathrm{kV}$. The images were recorded on TVIPS 1K x 1K CCD camera.

Characterization of $\mathrm{H}_{3} \underline{P} \mathrm{Po}_{12} \mathrm{O}_{40}$ nanoparticles by HRTEM. A sample of the $\mathrm{H}_{3} \mathrm{PMo}_{12} \mathrm{O}_{40}$ nanoparticle solution $(5 \mu \mathrm{L})$ was deposited on a carbon grid and blotted with filter paper. HRTEM and EFTEM (energy filtered TEM) were carried out on a Tecnai F-30 UT electron microscope operating at $300 \mathrm{KV}$. Elemental mapping was preformed using Gatan imaging filter (GIF). O-K, Cs- $\mathrm{M}_{4,5}$ and Mo- $\mathrm{L}_{3,2}$ ionization edges were used for the respective maps.

Oxidation reactions. All of the sulfides were used without purification as supplied by Aldrich. Thioanisole was tested for oxidation in temperatures of $80^{\circ} \mathrm{C}$ and $110^{\circ} \mathrm{C}$ and products were detected only at $110^{\circ} \mathrm{C}$. All of the reactions were carried out in $15 \mathrm{~mL}$ glass pressure tubes and put in a thermostated oil bath that was pre-heated to $110 \pm 2{ }^{\circ} \mathrm{C}$, for 16 hours. The catalyst/substrate ratio was 1:50 $2 \mu \mathrm{mol}$ catalyst and $0.1 \mathrm{mmol}$ substrate under 2 bar $\mathrm{O}_{2}$.

Figure S1. CDS/ $\mathrm{H}_{3} \mathrm{PMo}_{12} \mathrm{O}_{40}$ nanoparticles supported on hydrophilic silica.

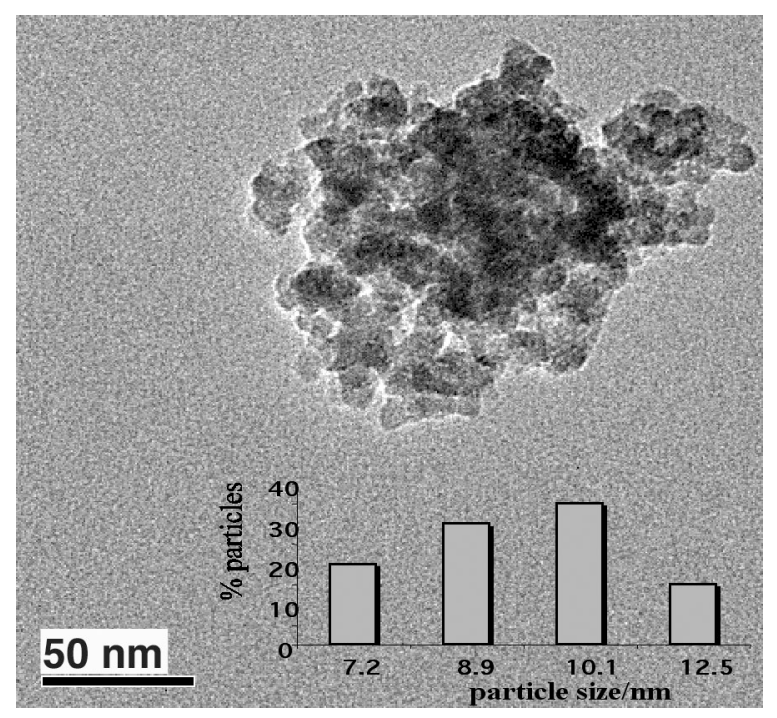

Figure S2. TEM of deposited $\mathrm{CDS} / \mathrm{H}_{5} \mathrm{PV}_{2} \mathrm{Mo}_{10} \mathrm{O}_{40} / \mathrm{PPG}$ nanoparticles

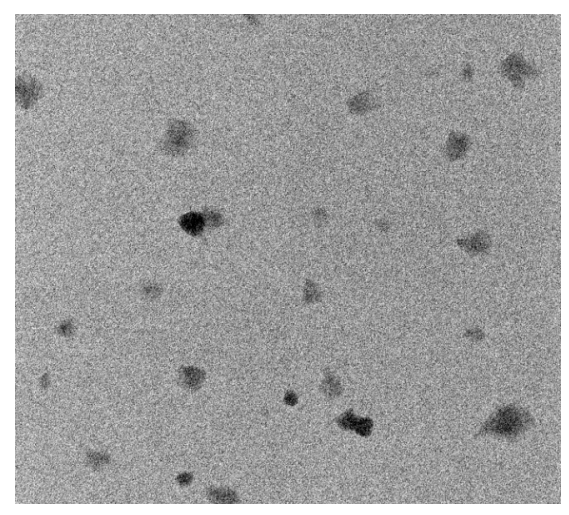

